Hybrid Instrument Development

for an Analytical Laboratory
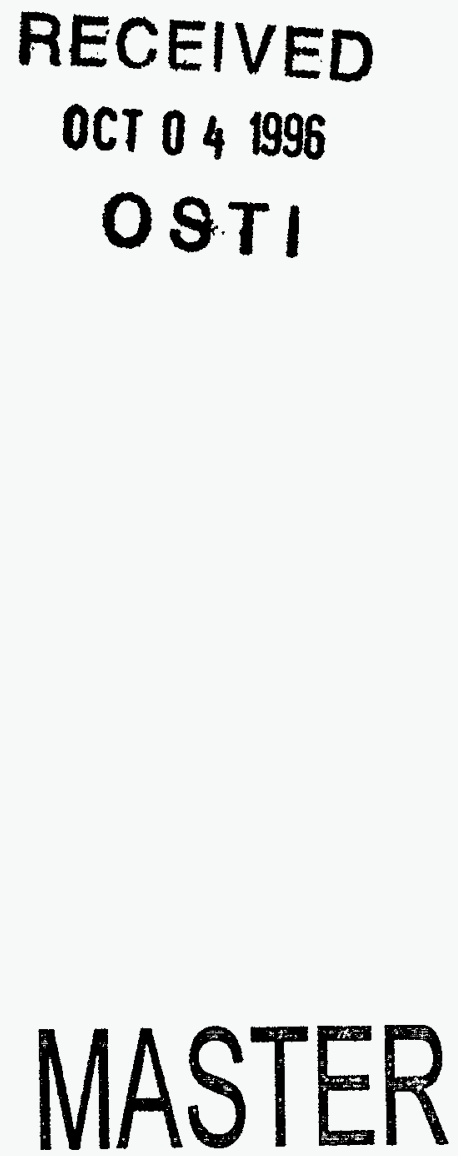

Los Alamos

Los Alamos National Laboratory is operated by the University of California for the United States Department of Energy under contract W-7405-ENG-36. 


\section{Edited by Chris Pearcy, Group CIC-1 \\ Prepared by Genara Jaramillo, Group NIS-5}

This work was supported by the U.S. Department of Energy, Office of Nonproliferation and National Security, Office of Safeguards and Security, and International Safeguards Division.

An Affirmative Action/Equal Opportunity Employer

This report was prepared as an account of work sponsored by an agency of the United States Government. Neither The Regents of the University of Califormia, the United States Government nor any agency thereof, nor any of their employees, makes any warranty, express or implied, or assumes any legal liability or responsibility for the accuracy, completeness, or usefulness of any information, apparatus, product, or process disclosed, or represents that its use would not infringe privately owned rights. Reference herein to any specific commercial product, process, or service by trade name, trademark, manufacturer, or otherwise, does not necessarily constitute or imply its endorsement, recommendation, or favoring by The Regents of the University of California, the United States Government, or any agency thereof. The views and opinions of authors expressed herein do not necessarily state or reflect those of The Regents of the University of California, the United States Government, or any agency thereof. The Los Alamos National Laboratory strongly supports academic freedom and a researcher's right to publish; therefore, the Laboratory as an institution does not endorse the viewpoint of a publication or guarantee its technical correctness. 
UC-714

Issued: August 1996

Hybrid Instrument Development

for an Analytical Laboratory

S.-T. Hsue

$M$. Collins

R. Cole

J. Sprinkle, Jr.

G. Walton

M. Miyauchi*

H. Okamoto*

S. Okazaki*

*Japan Atomic Energy Research Institute

DISTPIEUTION OF THIS DOCUMENT IS UNLIMITED

Los Alamos

NATIONAL LABORATORY

Los Alamos, New Mexico 87545 


\section{DISCLAIMER}

Portions of this document may be illegible in electronic image products. Images are produced from the best available original document. 


\section{CONTENTS}

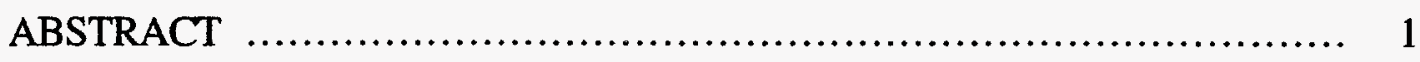

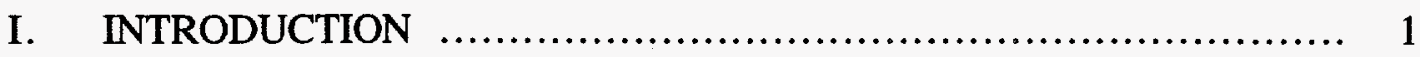

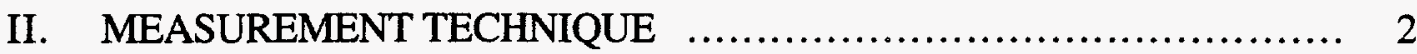

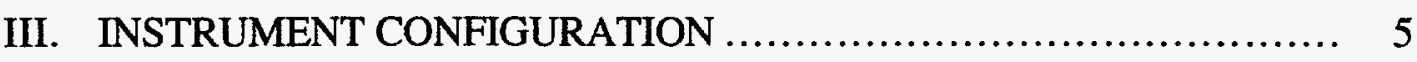

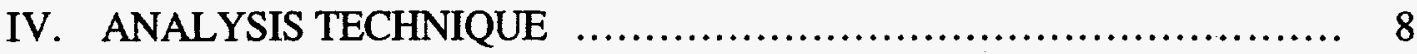

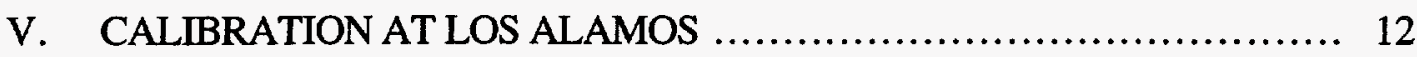

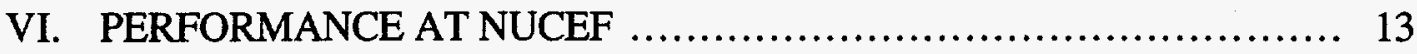

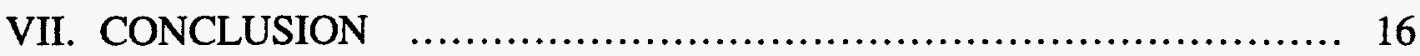

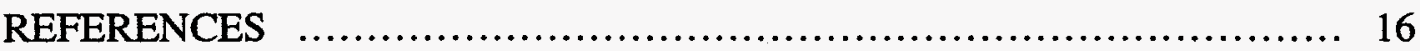




\title{
HYBRID INSTRUMENT DEVELOPMENT FOR AN ANALYTICAL LABORATORY
}

\author{
by \\ S.-T. Hsue, M. Collins, R. Cole, \\ J. Sprinkle, Jr., G. Walton \\ M. Miyauchi, H. Okamoto, and S. Okazaki
}

\begin{abstract}
We have been developing a hybrid densitometer for general laboratory application. This type of densitometer can be applied to concentration determinations of thorium, uranium, neptunium, plutonium, and americium. It can also be used to determine the ratios of any combination of these nuclear materials. This report describes the hardware and analysis approach. We will also describe some laboratory tests performed with the densitometer and present actual in-plant application results.
\end{abstract}

\section{INTRODUCTION}

The Nuclear Fuel Cycle Safety Engineering Research Facility (NUCEF) is a new facility built at the Japan Atomic Energy Research Institute (JAERI). The purpose of NUCEF is threefold: criticality safety studies, fuel reprocessing, and waste management. The criticality facilities include the Static Experiment Critical Facility (STACY) and the Transient Experiment Critical Facility (TRACY); both will be used to study solution fuels of uranium and plutonium.

As part of a research cooperation between the US Department of Energy (DOE) and JAERI, a hybrid K-edge/K x-ray fluorescence densitometer (HKED) was developed and fabricated by Los Alamos National Laboratory (LANL). The purpose of the instrument is to perform accountability measurements of uranium and plutonium or mixed solutions found in NUCEF. This instrument will be used by NUCEF for routine analytical laboratory accountability assays as well as for inspection purposes of the International Atomic Energy Agency (IAEA). We are also developing another HKED system for the Plutonium Facility analytical laboratory at Los Alamos.

The HKED has been in development for 10 years or more. ${ }^{1.2}$ Most of the development is concentrated on the application of the technique to verify uranium and plutonium concentrations in reprocessing plant dissolver solutions. The method is successful in several in-plant applications and has become an important tool for safeguarding reprocessing plants. This report describes our efforts in the last few years to develop the technique for use in analytical laboratories. The major difference between the two applications is that in the light-water-reactor reprocessing plant, the dissolver solution has a fairly narrow range in its uranium-to-plutonium ratio $(-100)$, and the uranium concentration $(200-250 \mathrm{~g} / 1)$ is also narrow. In analytical laboratories, the situation is 
different. The uranium and plutonium concentrations could vary from low $(\sim 10 \mathrm{~g} / \mathrm{l})$ to relatively high $(\sim 450 \mathrm{~g} / \mathrm{l})$. The uranium-to-plutonium ratio, therefore, may vary quite widely from 0.01 to 100. There may be other special nuclear material (SNM) elements present in the samples. Because of these differences, some of the assumptions made for the dissolver solution are no longer valid. In the past several years we have developed a general HKED, which is not bound by the above limitations.

This report describes the physics principles and software design of the hybrid system built for use in the analytical laboratory. We will also report on the mechanical design and finally the performance of the instrument both at Los Alamos during its development and also at NUCEF.

\section{MEASUREMENT TECHNIQUE}

The hybrid instrument combines two solution assay techniques-K-edge absorption densitometry (KED) and XRF - to determine concentrations of uranium, plutonium, and mixtures of the two elements in solutions.' The instrument employs the strengths of the two different techniques. KED has the advantage of relatively stable calibration; experience has shown that KED keeps its calibration for 4 to 5 years or longer. On the other hand, KED does not have wide dynamic range. In mixed solutions of uranium and plutonium, the minor isotope cannot be determined precisely by KED when the ratio exceeds 10 . The reason is that KED is determined by absorption, and when the ratio exceeds 10 , absorption due to the minor element is almost negligible. The XRF technique involves the excitation of uranium and plutonium atoms, and is better for determining the uranium-to-plutonium ratio. We have found that when the ratio is $\sim 100$, the minor element still can be determined to $\sim 1 \%$ or better. Therefore, the XRF technique has a better dynamic range than KED. In the hybrid system, KED is used to determine the concentration of the major isotope, and XRF technique is used to determine the ratios of SNM.

The KED technique is relatively insensitive to matrix variations and is accurate to $0.2-0.3 \%$. The technique measures the transmission of a tightly collimated photon beam through the sample; it is therefore quite insensitive to radiation emitted by the sample material. The technique is ideally suited to assay of the dissolver solutions as well as the uranium and plutonium product solutions of reprocessing plants.

The mass attenuation coefficient of each SNM element is discontinuous at its $\mathrm{K}$-absorption edge. The KED measures the transmission of $\mathrm{X}$-rays at energies above and below that of the Kabsorption edge. The purpose of the KED in this system is to measure the concentrations of the dominant SNM. Examples of spectra recorded by the K-edge detector in this system are shown in Fig. 1. The figure displays in logarithmic scale the spectral distribution for a blank ( $3 \mathrm{M} \mathrm{HNO}_{3}$ ) solution (reference spectrum) and from a uranium solution with $200 \mathrm{~g} / \mathrm{l}$ concentration. There is a characteristic decrease of the photon transmission at the K-absorption edge of uranium (115.6 $\mathrm{keV})$. The height of the jump is a function of the uranium concentration. The backgroundsubtracted assay spectrum divided by the background-subtracted reference spectrum, adjusted for the counting time difference, is the transmission at each channel. 


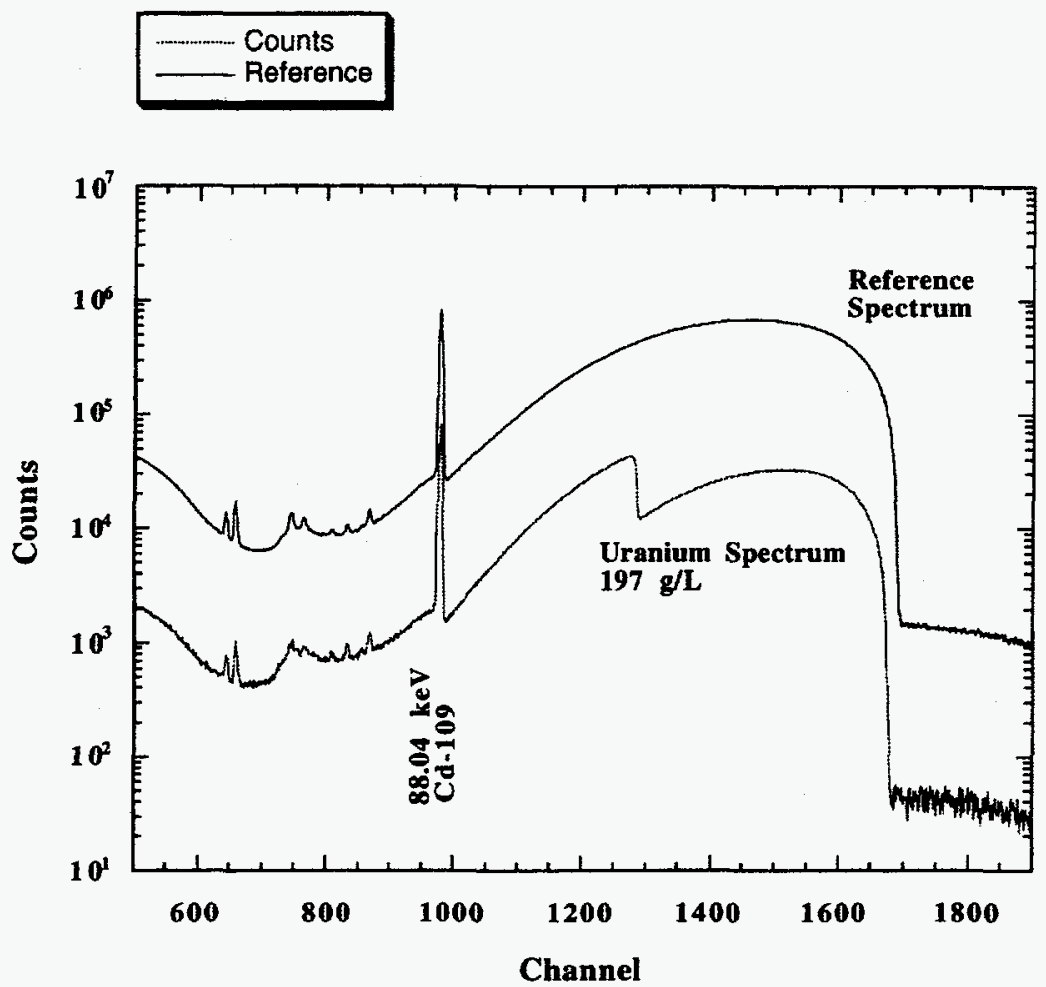

Fig. I. The top curve shows the reference spectrum. The bottom curve shows the sample spectrum from a uranium solution. The ratio of the sample spectrum to the reference spectrum gives the transmission of the solution.

There are a few gamma- and $\mathrm{x}$-ray peaks in the spectra of Fig. 1. The peaks at $22.10 \mathrm{keV}$ and $88.04 \mathrm{keV}$ come from the ${ }^{109} \mathrm{Cd}$ source close to the detector. These peaks are used for the digital stabilization of the detector gain.

Figure 2 shows the fitting region near the uranium edge. This plot shows the $\ln \ln (1 / T)$ versus $\ln (\mathrm{E})$. The transmission can be determined at the boundary of the fitting region or at the $\mathrm{K}$ absorption edge; the latter will give extrapolated assay results. The concentration can be determined by the equation:

$$
\rho(\mathrm{SNM})=\frac{1}{\Delta \mu \bullet d} \ln \left(\frac{T_{l}}{T_{u}}\right),
$$

where

$\rho(\mathrm{SNM})=$ concentration of the SNM in $\mathrm{g} / \mathrm{cc}$,

$\Delta \mu=$ difference of the mass absorption coefficients at the transmission energies,

$d=$ solution sample thickness,

$T_{1}=$ transmission below the absorption edge, and

$T_{u}=$ transmission above the edge. 


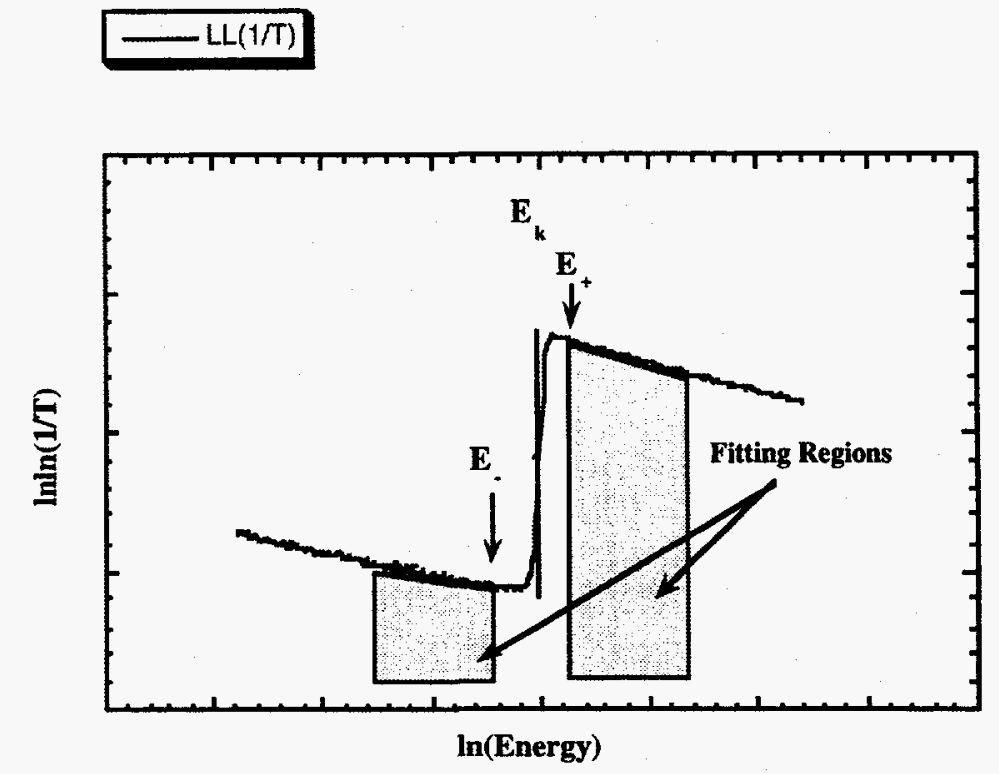

Fig. 2. The fitting region for a single-element solution. The fitting regions are 6-keV wide. The K-absorption-edge energy of the SNM is $E_{k}$.

The KED can also be used to determine both the uranium and plutonium concentrations simultaneously, if the ratio does not exceed 8 to 1 . For ratios exceeding 8 to 1 , the XRF is a much more precise method to determine SNM ratios. Once the ratio is determined, the concentration of the minor isotope can be calculated from the ratio and the concentration of the major isotope.

The purpose of the XRF measurement is to determine the ratios of SNM. Figure 3 shows a typical spectrum from a solution containing both uranium and plutonium. The broad "bump" of counts in the middle portion of the spectrum is due to inelastic scattering of the primary $\mathrm{x}$-ray beam, the largest contribution of which comes from the scattering off the low $Z$ elements of the sample.

The uranium/plutonium weight ratio can be determined from the measured net peak areas of the fluoresced $\mathrm{U}_{\mathrm{Ka} 1}$ and $\mathrm{Pu}_{\mathrm{Ka}}$ :

$$
\frac{U}{P u}=\frac{A t(\mathrm{U})}{A t(\mathrm{Pu})} \cdot \frac{\operatorname{Area}\left(\mathrm{U}_{\alpha 1}\right)}{\operatorname{Area}\left(\mathrm{Pu}_{\alpha 1}\right)} \cdot \frac{R_{e f f}\left(\mathrm{Pu}_{\alpha 1}\right)}{R_{e f f}\left(\mathrm{U}_{\alpha 1}\right)} \cdot \frac{1}{R_{U / P u}}
$$

where

At $=$ atomic weight of uranium and plutonium,

Area $=$ net peak area of the $K_{a 1} \mathrm{x}$-rays,

$R_{\text {eff }}=$ relative detection efficiency curve, and

$R_{\mathrm{U} / \mathrm{Pu}}=$ calibration factor describing the ratio of excitation probabilities for emission of $\mathrm{U}_{K \alpha 1}$ and $\mathrm{Pu}_{K \alpha 1} \mathrm{x}$-rays in the primary beam. 


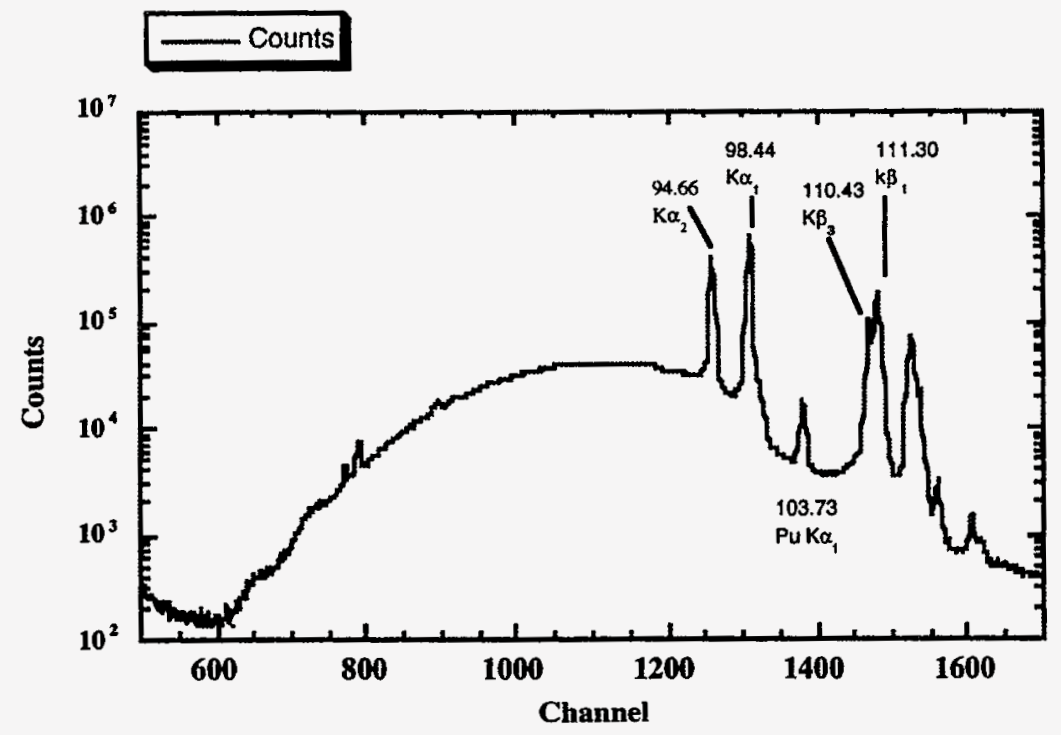

Fig. 3. The fluorescent spectrum from a sample containing a mixture of uranium and plutonium.

A response peak fitting technique is used to determine the peak areas of the $x$-rays, taking into account the line broadening of the $x$-rays because of their intrinsic natural width. Peak fitting is important in cases where the uranium/plutonium varies over a wide range of values.

\section{INSTRUMENT CONFIGURATION}

Figure 4 shows the overall view of the hybrid system at Los Alamos. Figure 5 shows the system after it is installed at NUCEF.

The design of the hybrid densitometer is shown schematically in Figs. 6 and 7; Figure 6 shows the top view; Fig. 7 shows the side view. The heart of the design is the sample changer.

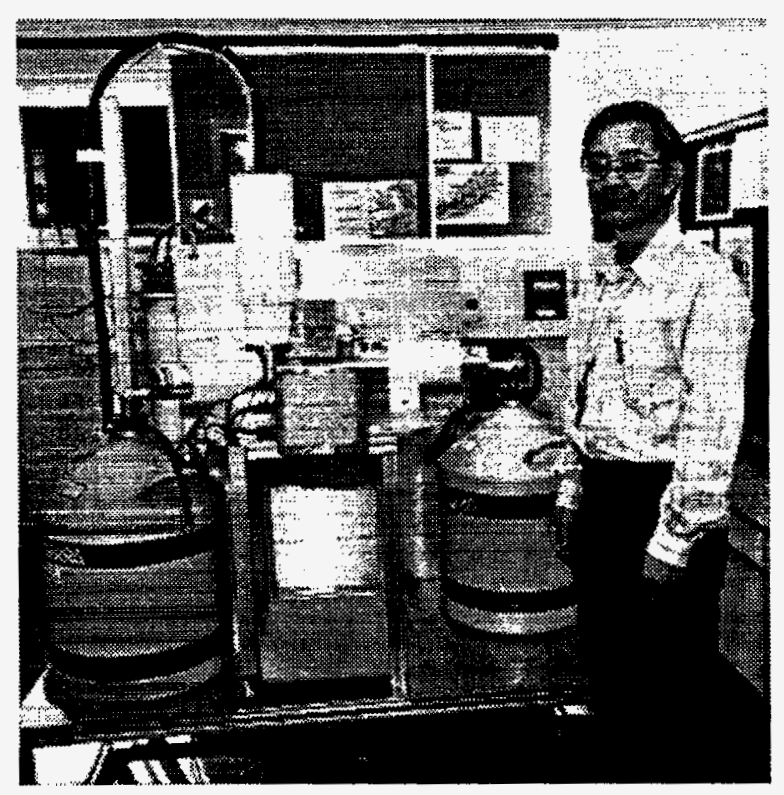

Fig. 4. The overall hybrid system at Los Alamos during development. 


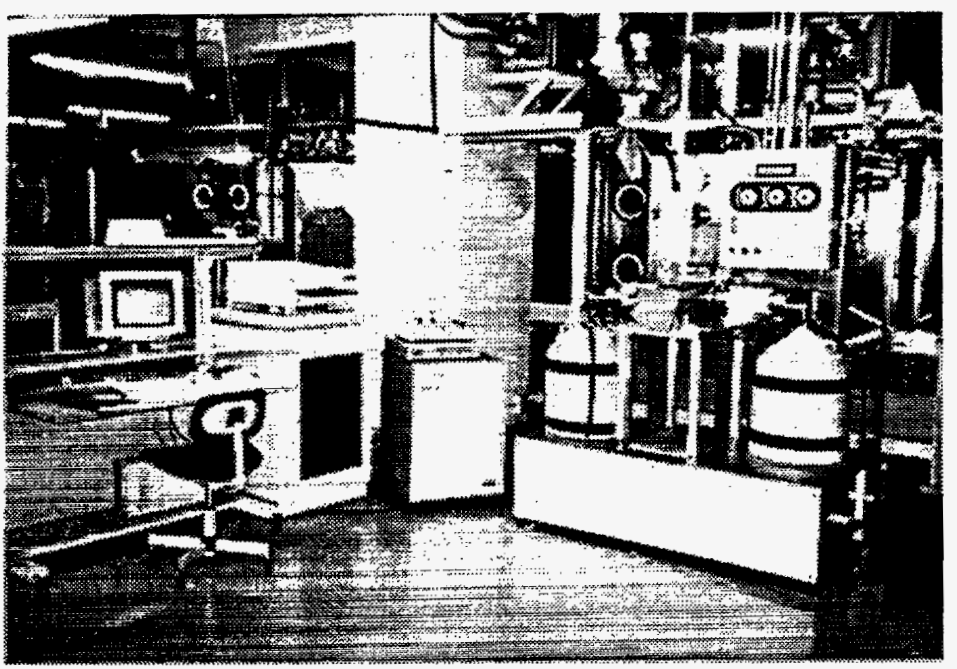

Fig. 5. The overall hybrid system after it was installed at the analytical laboratory at NUCEF.

The sample changer can accommodate a sample tray which holds up to six samples. The samples can be a 2-cm-path-length cell, 4-cm-path-length cell, or a mixture of both sizes. The sample tray is controlled by a "Compumotor" which in turn is controlled by computer. The absolute position of the sample cell can be reproduced to a standard deviation of $0.02 \mathrm{~mm}$. The sample changer is housed inside square stainless steel tubing which is bolted onto the glove box. The sample cells can be observed during the movement or assay through a leaded glass viewport, as shown in Fig. 8.

The x-ray tube is located outside of the glove box and irradiates the solution cells through a thin layer of stainless steel. The generator is in a tungsten housing (vertical cylinder shown on the

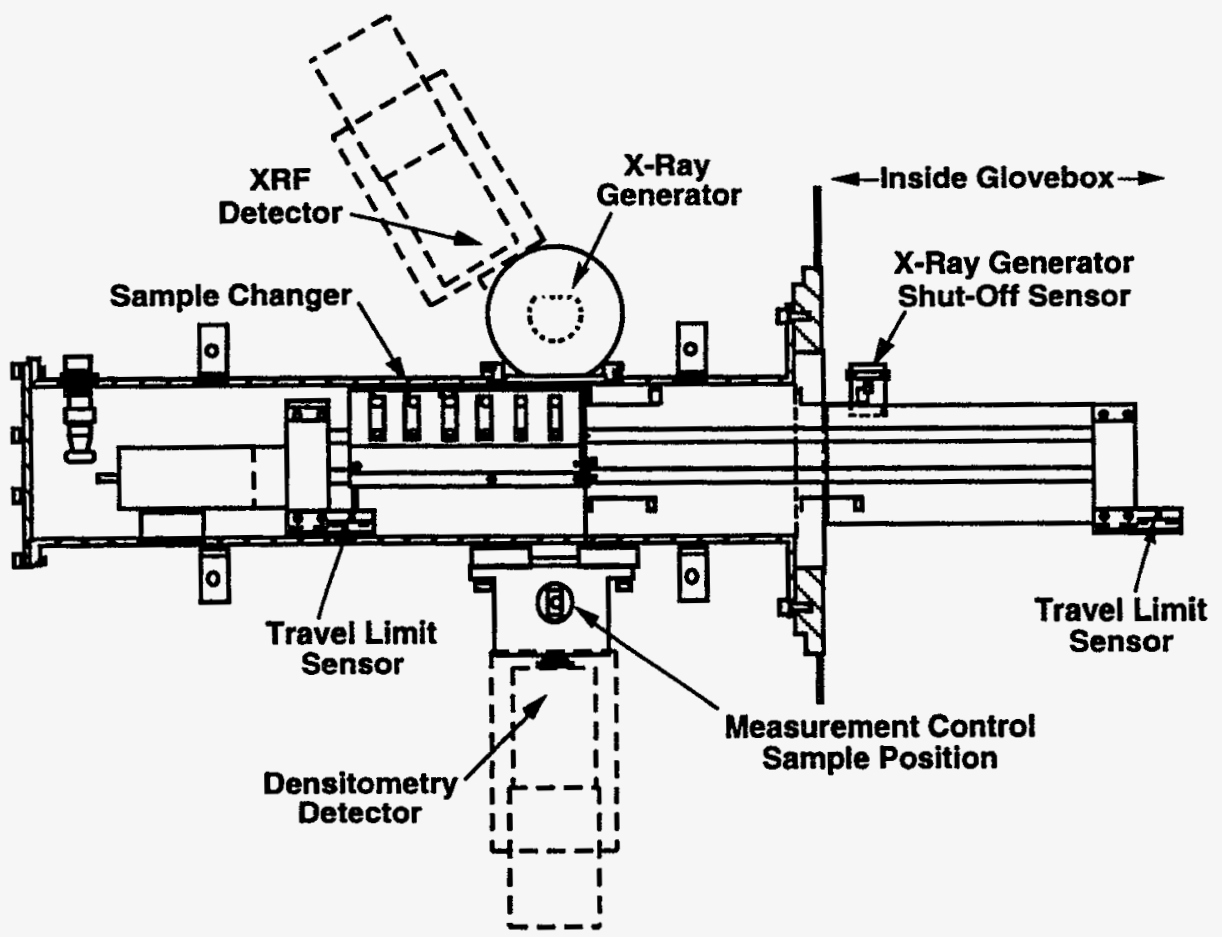

Fig. 6. Top view of schematic design of the hybrid hardware system. 


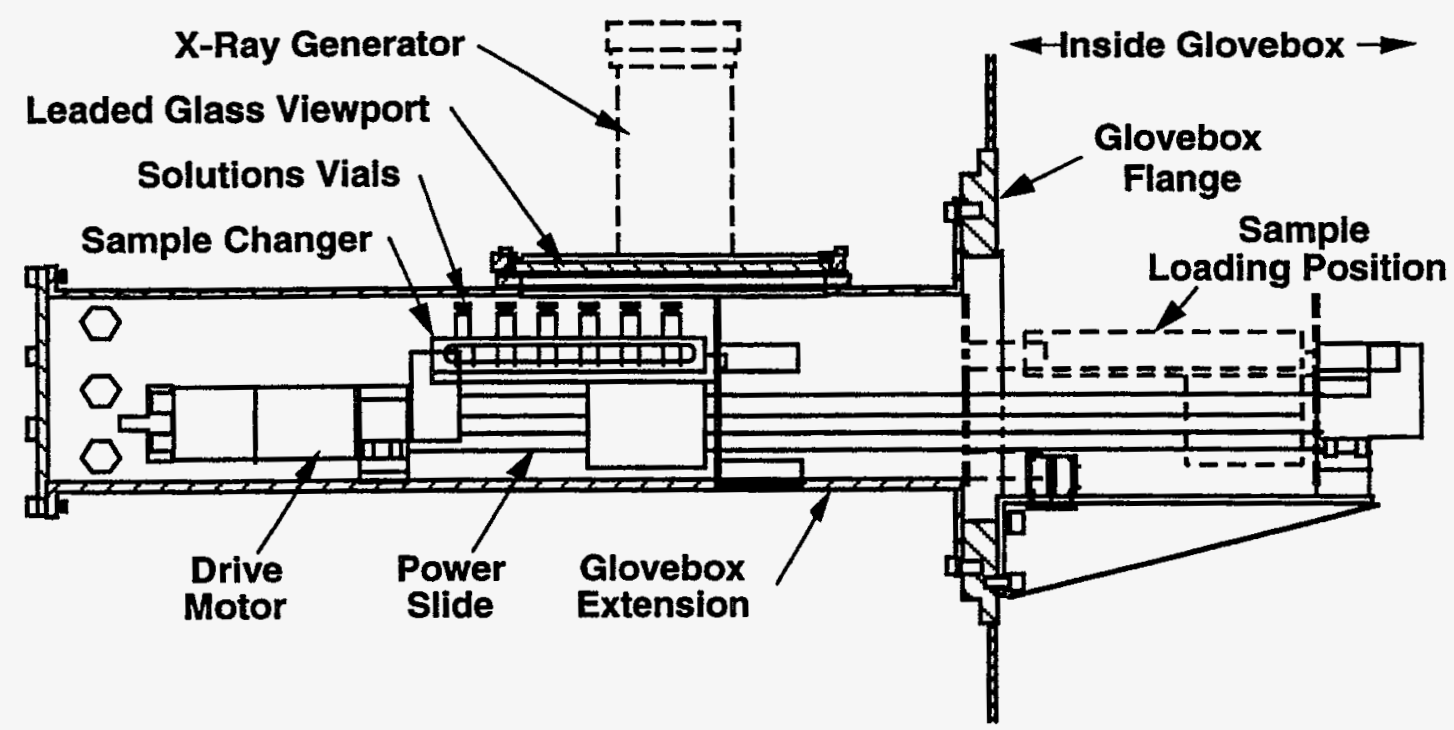

Fig. 7. Side view of schematic design of the hybrid hardware system.

right of Fig. 8), which reduces the radiation outside of the glove box to less than $2 \mathrm{mR} / \mathrm{h}$. The $\mathrm{x}-$ ray beam shines through the collimator and the solution sample. The transmission beam is measured by the KED detector, shown on the left of Fig. 8. The XRF is measured by the XRF detector behind the $\mathrm{X}$-ray tube. Figure 9 shows the sample tray in the loading position inside the glove box.

There are several safety features built into the system. At the end of the sample tray, a tungsten piece is installed to minimize $\mathrm{x}$-ray radiation and photon scattering into the glove box. When the sample tray is out of the tunnel and in the glove box, the $\mathrm{x}$-ray generator is shut off and cannot be operated. Also, if the cooling system for the generator fails, the generator automatically shuts off.

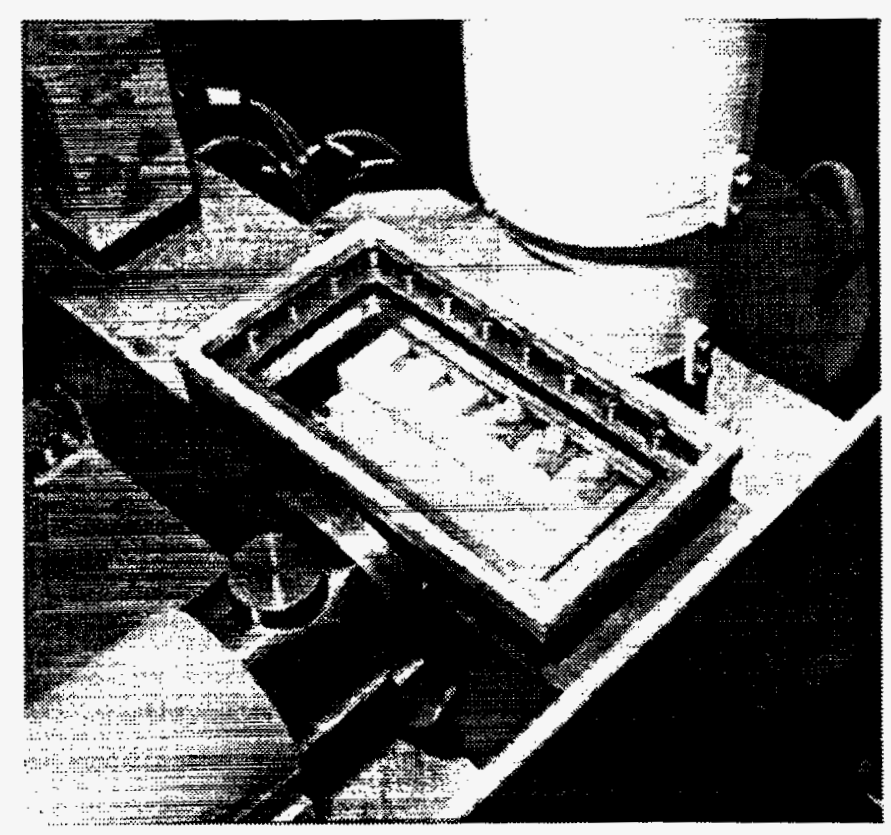

Fig. 8. Photograph of sample and sample tray in the $x$-ray beam. The vertical cylinder on the left is the housing for the x-ray tube. The horizontal tubing on the right is the KED detector. 

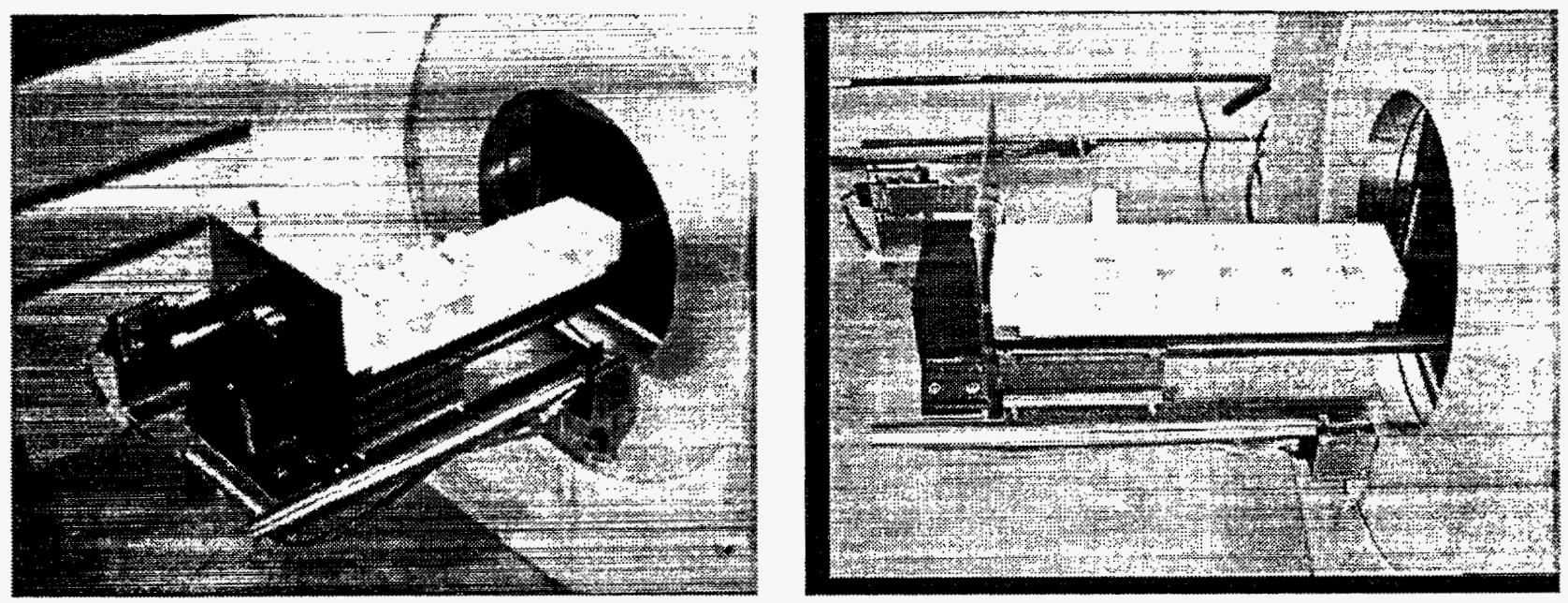

Fig. 9. The sample tray in loading position inside the glove box.

The X-ray machine is a Pantak Model HF-160 and can generate a $160 \mathrm{kV}$ x-ray beam. It is highly stable and has precise repeatability. The generator is controlled by the system computer to the voltage and current desired. The voltage is set at $150 \mathrm{kV}$ and the current is computer adjusted, depending on the sample, so that the counting rate is not excessive $(>40,000$ counts/s). A photograph of the generator is shown in Fig. 10.

The electronic components consist of a detector, which feeds its signal into an amplifier; the amplified signal, in turn, is analyzed and stored by a multichannel analyzer.

\section{ANALYSIS TECHNIQUE}

The measurement technique for KED was discussed earlier; KED analysis will now be examined in further detail. Recall from Eq. 1 that the density of a single element $\mathrm{Z}$ in a solution is

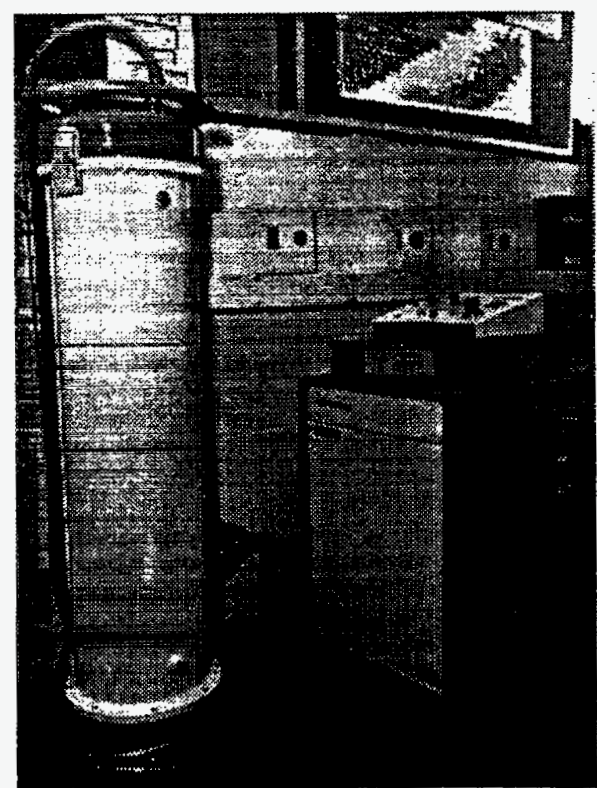

Fig. 10. The cathode and power supply of the $x$-ray generator. 
proportional to $\ln \left(T_{L} / T_{U}\right) . \quad T_{L}$ is the transmission of the $x$-ray beam through the solution at an energy below the $\mathrm{K}$-edge; $\mathrm{T}_{\mathrm{U}}$ is the transmission at an energy above the edge. If our detector had perfect resolution, we would see a sharp drop in $T$ at the $K$-edge. We could obtain $T_{L}$ and $T_{U}$ from channels adjacent to the edge, and substitution into Eq. 1 would yield $\rho(Z)$.

A real detector has limited resolution, however, creates a "rounded" K-edge in the spectrum. This rounding of the edge makes it impossible to measure $T_{L}$ and $T_{U}$ in the immediate vicinity of the edge. Suppose $E_{L}$ is an energy just below, and $E_{U}$ is just above, the rounded part of the $K-$ edge. $T_{L}$ can be obtained by performing a least-squares linear fit on data in a region below $E_{L}$, and $T_{U}$ from data in a region above $E_{U}$. A plot of $T$ versus $E$ would not be useful for such fits, because the function is not linear on either side of the edge. Because of the energy dependence of gammaray cross sections, a plot of $\ln \ln (1 / T)$ versus $\ln (E)$ does result in a linear function on both sides of the K-edge (see Fig. 2). The $E_{L}$ intercept of the lower fit is used to calculate $T_{L} ; T_{U}$ is obtained similarly from the upper fit. The fitted $T_{L}$ and $T_{U}$ are substituted into Eq. 1, yielding $\rho(Z)$. In this case, $\Delta \mu$ represents the difference in mass attenuation coefficients for element $Z$ at energies $E_{L}$ and $\mathrm{E}_{v}$, not at the edge itself.

The above technique applies to solutions which contain a single SNM element. Presence of minor SNM elements can create a bias in the linear fitting performed on the major element. For example, the thorium K-edge happens to lie within the lower fit window for uranium (see Fig. 11). Also, the plutonium K-edge is positioned within the upper fit window for uranium. Shrinking the uranium fit windows to avoid the thorium and/or plutonium edges would result in decreased precision, because the fitting would be done using fewer data points. The single-element technique does not tell us the concentrations of minor elements or correct for their attenuation effects. We

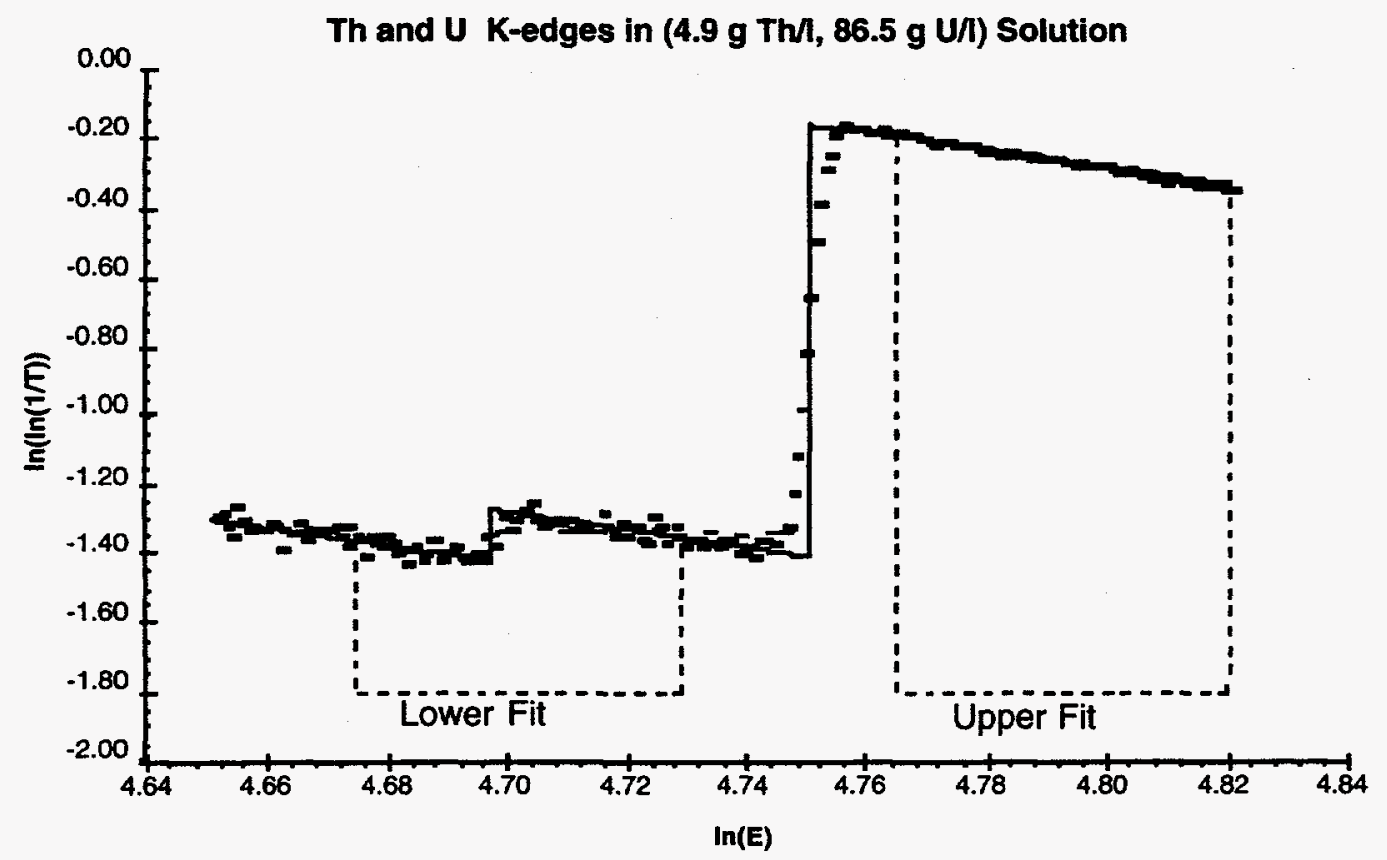

Fig. 11. Fitting regions for a single element as applied to a solution with mixed SNM. 
have developed a new method to analyze KED data; this method, the known-ratio technique, ${ }^{3}$ improves the precision of measurement and provides a better method to correct for bias due to minor elements.

For many solutions, the ratios of the elements can be determined by another measurement (such as XRF); only the concentrations need be determined. The known-ratio technique uses known SNM ratios and mass attenuation functions to "strip out" the effects of minor elements. The single-element technique is used to provide an initial (biased) estimate of major element concentration. The estimated major element concentration and the known ratios are used to estimate the concentrations of the minor elements. Mathematical "de-attenuation" is performed on the original transmission data, channel by channel, using the estimated concentration of each minor element. The de-attenuated transmission data is analyzed using the single-element technique, and a refined estimate of major element concentration is obtained. This process is repeated a few times, while the major element concentration converges upon its final value. The minor element concentrations are then calculated using the known ratios. An example of the fixed-ratio technique is shown in Fig. 12. Details of the technique can be found in Ref. 3.

In the section on measurement techniques, generalized XRF analysis was discussed. Now we will examine XRF analysis in greater detail. Recall from Eq. 2 that the U/Pu ratio is inversely proportional to $R_{U / P u} \bullet R_{U / P u}$ is a calibration factor which incorporates the ratio of excitation probabilities for emission of $\mathrm{U}_{\alpha 1}$ and $\mathrm{Pu}_{\alpha 1} \mathrm{x}$-rays in the primary beam. In the application of HKED to a dissolver solution, the assumption is made that the U/Pu ratio is 100 . With this assumption, the $\mathbf{R}_{\mathbf{U} / \mathbf{u}}$ is a simple exponential function of uranium concentration. For general

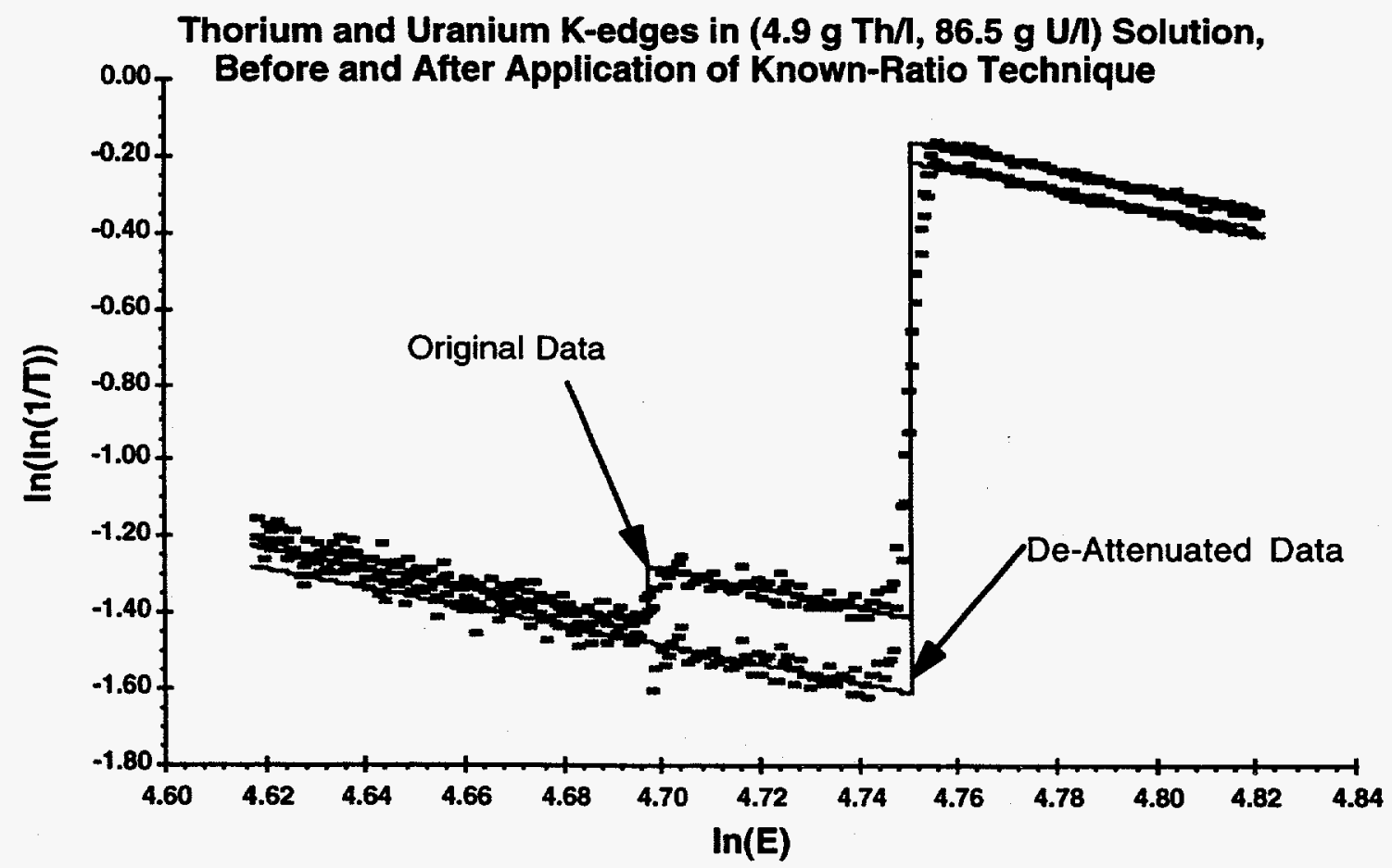

Fig. 12. Thorium and uranium mixed solution. The top curve shows the original data; the bottom curve shows the de-attenuated data using the known-ratio technique. 
laboratory application, this assumption is no longer valid. In our XRF analysis, the calibration factor for numerator element $Z_{1}$ and denominator element $Z_{2}$ can be expressed as follows:

$$
R_{z_{1} / z_{2}}=\frac{W\left(Z_{1}, \alpha_{1}\right)}{W\left(Z_{2}, \alpha_{1}\right)}
$$

where

$W\left(Z_{l}, \alpha_{1}\right)=$ attenuation-corrected excitation integral for $K_{\alpha l}$ peak of element $Z_{l}$, and

$W\left(Z_{2}, \alpha_{1}\right)=$ attenuation-corrected excitation integral for $K_{\alpha l}$ peak of element $Z_{2}$.

The $W$ integral for element $Z$ and $\mathrm{x}$-ray peak $P$ takes the following factors into account:

- the spectral distribution of the $x$-ray beam,

- the photoelectric cross section of element $Z$ as a function of energy,

- estimated concentration of each SNM element in solution,

- attenuation due to the sample itself and the materials between the tube and sample,

- energy of peak $P$,

- K-edge energy of element $Z$,

- depth of sample as viewed from XRF detector, and

- angle between incident beam and XRF detector axis. W is calculated by numerical integration. This method is valid for any SNM concentration and combination of SNM in solution and is applicable to laboratory application.

The examples of XRF analysis cited in this paper focus mainly on the U/Pu ratio. In fact, the technique described in Eqs. 2 and 3 can be applied to other elements and ratios. Other ratios of interest include $\mathrm{U} / \mathrm{Th}, \mathrm{Pu} / \mathrm{Np}$, and $\mathrm{Pu} / \mathrm{Am}$. Let $Z_{1}$ represent the numerator element and $Z_{2}$ the denominator element. The ratio of the two elements' concentrations can be calculated as follows:

$$
\frac{Z_{1}}{Z_{2}}=\frac{\operatorname{At}\left(\mathrm{Z}_{1}\right)}{\operatorname{At}\left(\mathrm{Z}_{2}\right)} \cdot \frac{\operatorname{Area}\left(Z_{1}, \alpha_{1}\right)}{\operatorname{Area}\left(Z_{2}, \alpha_{1}\right)} \cdot \frac{R_{e f f}\left(Z_{2}, \alpha_{1}\right)}{R_{e f f}\left(Z_{1}, \alpha_{1}\right)} \cdot \frac{1}{R_{Z_{1}, Z_{2}}}
$$

where

$$
\begin{aligned}
& \operatorname{At}(Z)=\text { atomic weight of element } Z \\
& \operatorname{Area}\left(Z, \alpha_{l}\right)=\text { area of } K_{\alpha l} \text { peak for element } Z \\
& R_{e f f}\left(Z, \alpha_{l}\right)=\text { relative efficiency of detector at energy of } K_{\alpha l} \text { peak for element } Z \text {, and } \\
& R_{Z_{l} / Z_{2}}=\text { XRF calibration factor corresponding to } Z_{1} / Z_{2^{*}}
\end{aligned}
$$


The method for calculating the XRF calibration factor in Eq. 3 is noteworthy because it applies to ratios involving arbitrary numerator and denominator SNM elements, with arbitrary concentrations. The XRF calibration implemented for dissolver solutions by $\mathrm{H}$. Ottmar ${ }^{1,2}$ in Germany, for example, assumes a fixed U/Pu ratio of 100/1. Analysis using the W integral allows a degree of flexibility not found in other techniques: the ability to apply a uniform technique to solutions which have a wide variety of SNM content and concentrations.

An interesting aspect of the HKED analysis is that KED analysis, especially the fixed-ratio technique, depends on the ratio of SNM. On the other hand, the generalized XRF technique requires a knowledge of the concentration of SNM in order to calculate the $R_{Z_{1} / z_{2}}$. The interdependence of the two techniques suggests iteration of the two calculations to arrive at the final results of the HKED assay.

\section{v. CALIBRATION AT LOS ALAMOS}

The performance of the hybrid system was checked at LANL before shipment. A set of eight uranium solution standards was prepared at the Safeguards Analytical Laboratory of the IAEA. The density and concentration of the standards are shown in Table I. The make-up concentrations have been verified by Davis Gray potentiometric titration. The higher concentration standards are in the 2-cm cells (2A_); the lower concentration standards are in the 4-cm cells (4A_). The concentrations are given at a temperature of $25^{\circ} \mathrm{C}$; the measured concentrations have also been corrected to the same temperature. These concentrations were based on an initial $\Delta \mu$ value of 3.3331 .

These samples were measured in the internal sample tray of the hybrid system. Each of the standards was measured five times, with a 1000-s live time for each run. Table II lists the results of these measurements.

From these measurements and averages, the $\Delta \mu$ value of the $2-\mathrm{cm}$ cell was found to be 3.3241 and the $\Delta \mu$ value of the $4-\mathrm{cm}$ cell was found to be 3.3528. The two values differ by $\sim 1 \%$, which is understandable because scattering in the $2-\mathrm{cm}$ cell is substantially different from the 4-cm cell. A plot of the measured ratios is shown in Fig. 13. We should point out that the $\Delta \mu$ value of 3.3331 was obtained by Ottmar, et al., ${ }^{2}$ with a completely different design, setup and set of

\begin{tabular}{|l|c|c|c|}
\hline \hline \multicolumn{4}{|c|}{$\begin{array}{l}\text { Table I. Uranium Solution Standard Used to Calibrate the } \\
\text { Hybrid System at Los Alamos }\end{array}$} \\
\hline \multicolumn{1}{|c|}{ Standard ID } & $\begin{array}{c}\text { Weight } \% \\
\text { U }\end{array}$ & $\begin{array}{c}\text { Density } \\
\left(\mathbf{g} / \mathbf{c m}^{\mathbf{3}}\right)\end{array}$ & $\begin{array}{c}\text { Concentration } \\
(\mathbf{g} / \mathbf{I})\end{array}$ \\
\hline 2A_359 & 22.392 & 1.6027 & 358.88 \\
\hline 2A_180,4A_180 & 13.756 & 1.3099 & 180.19 \\
\hline 2A_115,4A_115 & 9.620 & 1.1989 & 115.33 \\
\hline 2A_60,4A_60 & 5.461 & 1.1035 & 60.26 \\
\hline 4A_33 & 3.111 & 1.0557 & 32.84 \\
\hline
\end{tabular}




\begin{tabular}{|l|c|c|c|c|}
\hline \hline \multicolumn{6}{|c|}{$\begin{array}{c}\text { Table II. Uranium Calibration Measurement of Standard } \\
\text { Solutions Performed at Los Alamos }\end{array}$} & $\begin{array}{c}\text { Known } \\
\text { Conc. } \\
\text { (g/l) }\end{array}$ & $\begin{array}{c}\text { Meas. } \\
\text { Conc. } \\
\text { (g/1) }\end{array}$ & $\begin{array}{c}\text { Meas. } \\
\text { Error } \\
(\%)\end{array}$ & $\begin{array}{c}\text { Ratio(Meas. } \\
\text { /Known) }\end{array}$ \\
\hline 2-cm cells & & & & \\
\hline 2A_60_01 & 60.26 & 60.032 & 0.20 & 0.996 \\
\hline 2A_60_02 & 60.26 & 59.992 & 0.21 & 0.996 \\
\hline 2A_115_01 & 115.33 & 114.908 & 0.13 & 0.996 \\
\hline 2A_115_02 & 115.33 & 115.479 & 0.12 & 1.001 \\
\hline 2A_180_01 & 180.19 & 179.497 & 0.10 & 0.996 \\
\hline 2A_180_02 & 180.19 & 179.878 & 0.10 & 0.998 \\
\hline 2A_359_03 & 358.88 & 355.516 & 0.10 & 0.991 \\
\hline 4-cm cells & & & & \\
\hline 4A_33_01 & 32.84 & 33.100 & 0.23 & 1.008 \\
\hline 4A_33_02 & 32.84 & 33.099 & 0.22 & 1.008 \\
\hline 4A_60_01 & 60.26 & 60.600 & 0.15 & 1.006 \\
\hline 4A_60_02 & 60.26 & 60.364 & 0.15 & 1.002 \\
\hline 4A_115_01 & 115.33 & 116.145 & 0.11 & 1.007 \\
\hline 4A_115_02 & 115.33 & 115.932 & 0.13 & 1.005 \\
\hline 4A_180_01 & 180.19 & 182.132 & 0.13 & 1.011 \\
\hline 4A_180_02 & 180.19 & 182.331 & 0.13 & 1.012 \\
\hline
\end{tabular}

standards. The fact that our calibration of 3.3241 differs only by $<0.3 \%$ implies the universality of the densitometry calibration to within $0.5 \%$. If one is satisfied with a bias of $<0.5 \%$, then no calibration is necessary. To obtain a bias less than $0.5 \%$, a separate calibration for each instrument is required. The precision of KED measurements is shown in Fig. 14.

\section{PERFORMANCE AT NUCEF}

The hybrid instrument was shipped to Japan at the end of 1993 and installed at the analytical laboratory of NUCEF in early 1994. After the glove box in which the densitometer was installed was checked by government, we returned to NUCEF to perform the instrument test in early 1995 . Table III is a comparison between the chemical analysis and hybrid assay. Each standard was measured with three 1000 -s measurements.

From this set of measurements, the HKED seems to have a slight bias. The $\Delta \mu$ value was adjusted based on this set of measurements. After the adjustment, NUCEF ran another set of uranium standards with HKED. The results are shown in Table IV and Fig. 15. We found that for 2 -cm cells, the concentration can be determined with a bias of less than $0.3 \%$ for concentrations ranging from $50 \mathrm{~g} / \mathrm{l}$ to $500 \mathrm{~g} / \mathrm{l}$. The lower concentration samples can be assayed with smaller bias if 4 -cm cells are used. 


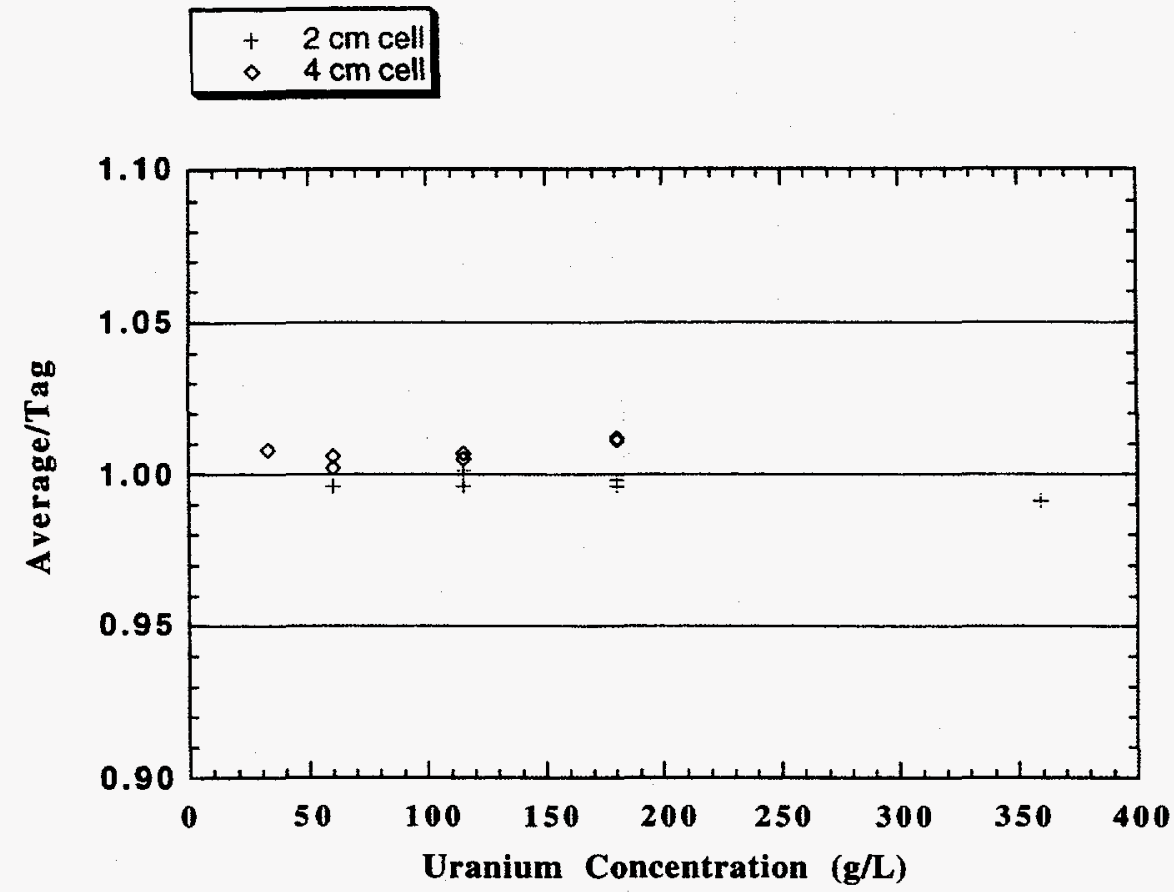

Fig. 13. Calibration measurement at Los Alamos based on uranium solutions prepared at Sibersdorf Analytical Laboratory.

\begin{tabular}{|c|c|c|c|c|}
\hline $\begin{array}{c}\text { DG Assay } \\
(\mathrm{gU} / \mathbf{1})\end{array}$ & $+1-$ & $\begin{array}{c}\text { HKED Meas. } \\
(\mathrm{gU} / \mathrm{l})\end{array}$ & $+1-$ & $\begin{array}{c}\text { HKED/DG } \\
\text { Ratio }\end{array}$ \\
\hline \multicolumn{5}{|l|}{$2-\mathrm{cm}$ cell } \\
\hline 11.86 & 0.02 & 12.25 & 0.23 & 1.033 \\
\hline 52.91 & 0.01 & 53.26 & 0.25 & 1.007 \\
\hline 118.8 & 0.04 & 119.60 & 0.28 & 1.007 \\
\hline 223.0 & 0.11 & 225.00 & 0.40 & 1.008 \\
\hline 313.2 & 0.17 & 316.40 & 0.58 & 1.010 \\
\hline 357.3 & 0.43 & 361.3 & 0.65 & 1.011 \\
\hline 402.5 & 0.27 & 408.1 & 0.85 & 1.014 \\
\hline 453.9 & 0.18 & 461.0 & 1.11 & 1.016 \\
\hline \multicolumn{5}{|l|}{ 4-cm cell } \\
\hline 52.91 & 0.01 & 52.76 & 0.31 & 0.997 \\
\hline 118.8 & 0.04 & 118.6 & 0.25 & 0.999 \\
\hline
\end{tabular}




\begin{tabular}{|c|c|c|c|c|}
\hline $\begin{array}{c}\text { DG Assay } \\
(\mathrm{g} U / 1)\end{array}$ & +1 & $\begin{array}{c}\text { HKED Meas. } \\
\text { (gU/l) }\end{array}$ & +1 & $\begin{array}{c}\text { HKED/DG } \\
\text { Ratio }\end{array}$ \\
\hline \multicolumn{5}{|l|}{$2-\mathrm{cm}$ cell } \\
\hline 10.42 & 0.01 & 10.65 & 0.24 & 1.022 \\
\hline 49.95 & 0.03 & 50.23 & 0.24 & 1.006 \\
\hline 102.2 & 0.03 & 102.1 & 0.26 & 0.999 \\
\hline 197.8 & 0.17 & 197.9 & 0.40 & 1.001 \\
\hline 289.9 & 0.10 & 289.6 & 0.51 & 0.999 \\
\hline 320.1 & 0.43 & 319.1 & 0.56 & 0.997 \\
\hline 398.5 & 0.09 & 397.8 & 0.80 & 0.998 \\
\hline 480.6 & 0.11 & 481.8 & 1.14 & 1.003 \\
\hline \multicolumn{5}{|l|}{ 4-cm cell } \\
\hline 10.42 & 0.01 & 10.42 & 0.13 & 1.000 \\
\hline 49.95 & 0.03 & 49.93 & 0.15 & 1.000 \\
\hline 102.2 & 0.03 & 101.9 & 0.23 & 0.997 \\
\hline
\end{tabular}

Hybrid Densitometer (1000-s Assay)

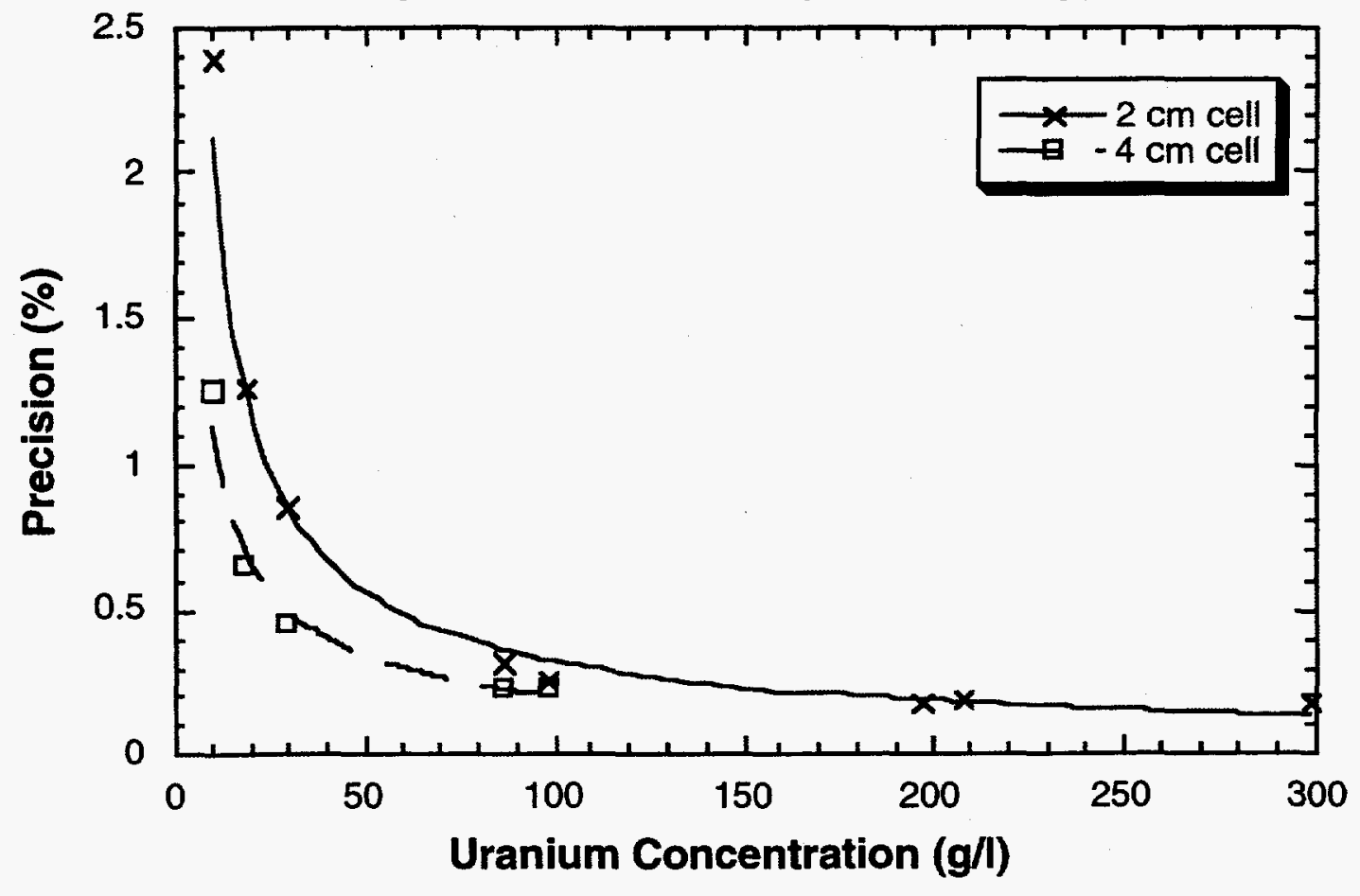

Fig. 14. Measurement precision of KED in the hybrid densitometer. 


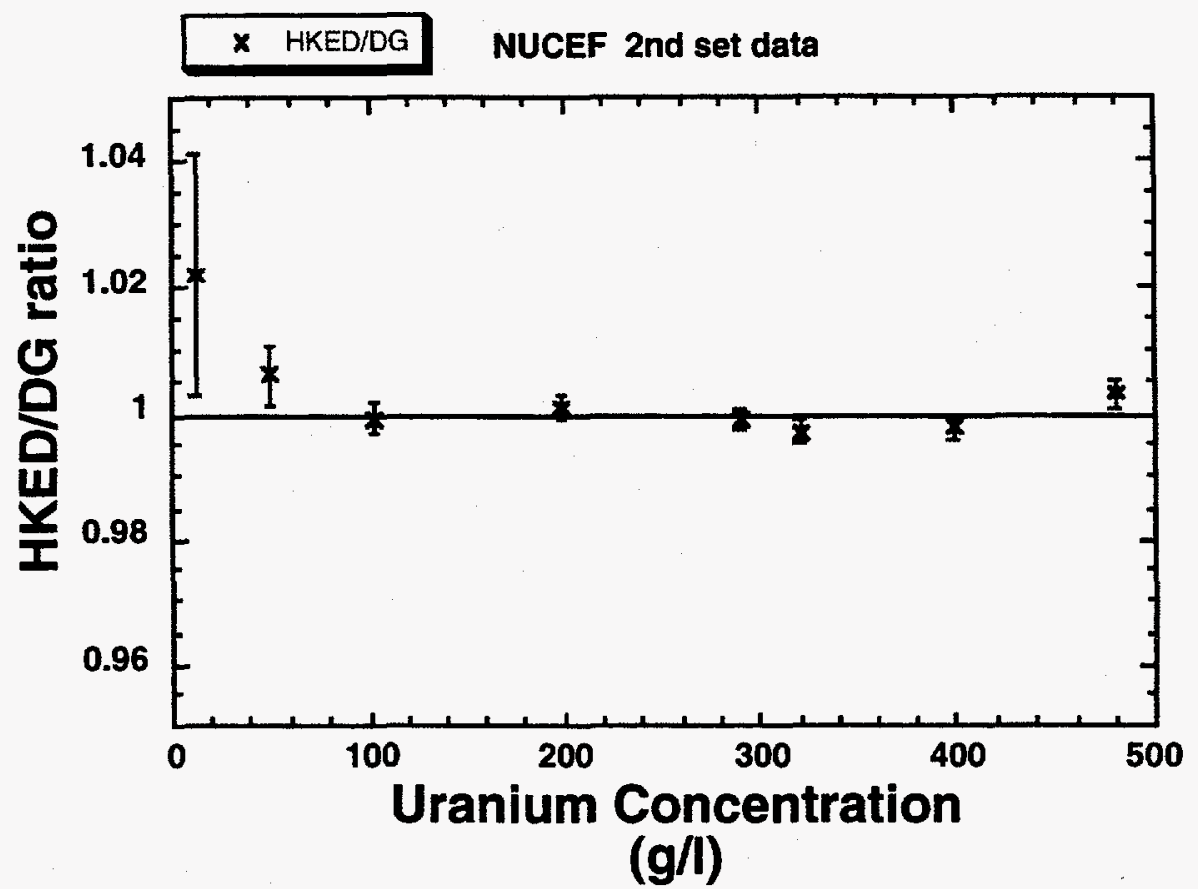

Fig. 15. Comparison between chemical determination and HKED assay at NUCEF.

\section{CONCLUSION}

This report describes the development of hybrid instrument for general laboratory application. We found that the hybrid instrument can be designed and developed for a wide range of applications in assaying concentrations of thorium, uranium, neptunium, plutonium, and americium from $10 \mathrm{~g} / 1$ to $500 \mathrm{~g} /$. Using data from measurements at Los Alamos and NUCEF, we found that for 1000-s assays of single-element solutions with high concentrations, a bias of less than $0.2 \%$ and a precision of $0.2 \%$ can be achieved. We have extended the capabilities of HKED to assaying mixtures of these elements with ratios ranging from 100 to 0.01 simultaneously without the need for chemical separation.

\section{REFERENCES}

1. H. Ottmar and H. Eberle, "The Hybrid K-Edge/ K-XRF Densitometer: Principles - Design Performance," Kernforschungszentrum Karlsruhe report KfK 4590 (February 1991).

2. H. Ottmar, H. Eberle, E. M. Schott, J. Salaun, P. Grison, M. Ougier, H. Wagner, J. Goerten, G. Ballette, and P. Louis, "The Use of the Hybrid K-edge Densitometer for Routine Analysis of Safeguards Verification Samples of Reprocessing Input Liquor," Proceedings of the 13th ESARDA Symposium on Safeguards and Nucl. Mater. Manage. (ESARDA, Ispra, Italy, 1991), Vol. 24, pp. 337-344.

3. S.-T. Hsue and M. Collins, "New Analysis Technique for K-Edge Densitometry Spectra," presented at the American Nuclear Society "Fifth International Conference on Facility Operations-Safeguards Interface," Jackson Hole, Wyoming, September 24-29, 1995. 
This report has been reproduced from the best available copy.

It is available to DOE and DOE contractors from the Office of Scientific and Technical Information,

P.O. Box 62,

Oak Ridge, TN 37831.

Prices are available from

(615) 576-8401.

It is available to the public from the

National Technical Information Service,

US Department of Commerce,

5285 Port Royal Rd.,

Springfield, VA 22161. 